\title{
Antioxidant Capacity and Flavonoid Content in Wild Strawberries
}

\author{
Shiow Y. Wang ${ }^{1}$ and Kim S. Lewers \\ U.S. Department of Agriculture, Agricultural Research Service, Beltsville Agricultural Research \\ Center, Fruit Laboratory, Bldg. 010A, BARC-West, 10300 Baltimore Avenue, Beltsville, \\ MD 20705-2350
}

\begin{abstract}
AdDitional INDEX words. Fragaria, genotypes, anthocyanin, phenolics, free radicals
Abstract. Fruit of the cultivated strawberry (Fragaria $\times$ ananassa Duchesne ex Rozier) are a good source of natural antioxidants, which play an important role in protecting human health. Antioxidant levels vary considerably among strawberry genotypes. The cultivated strawberry is a hybrid of two very different wild progenitor species: $F$. virginiana Mill. and $F$. chiloensis (L.) Mill. The progenitor species are valued by strawberry breeders as sources of novel traits, but have not been evaluated for antioxidant capacity or levels of antioxidant compounds. The objectives of this study are 1) to evaluate the antioxidant contents and antioxidant activities in representatives of $F$. virginiana and $F$. chiloensis in comparison with representatives of the cultivated strawberry species $(F$. $\times$ ananassa $)$, 2) to determine which strawberry compounds are most closely correlated with antioxidant capacity among these three species, and 3) to identify wild strawberry genotypes with high antioxidant activity and bioactive compounds for use in cultivar development. Fruit of 19 accessions from each of the three species, cultivated strawberry plus the two progenitor species ( $F$. $\times$ ananassa, $F$. virginiana, and $F$. chiloensis), were evaluated for levels of antioxidant capacity (oxygen radical absorbance capacity), total phenolics, total anthocyanins, ellagic acid, quercetin 3-glucoside plus quercetin 3-glucuronide, kaempferol 3-glucoside, kaempferol 3-rutinoside, p-coumaryl-glucose, pelargonidin 3glucoside, pelargonidin 3-glucoside-succinate, cyanidin 3-glucoside, and cyanidin 3-glucoside-succinate. Fruit of the 13 accessions tested from the wild progenitor species $F$. virginiana had significantly higher antioxidant capacity, total phenolics, and total anthocyanins than did the fruit of three accessions tested from the cultivated strawberry $F$. $\times$ ananassa, or the three accessions tested from the other wild progenitor species (F. chiloensis), and will be valuable as a source of parent material for developing more nutritious strawberry cultivars. The high correlation with antioxidant capacity, relative efficiency, and lack of genotype-by-year interaction in this study suggests that the measurement of total phenolics may be the better assay to use for the later selection stages in a strawberry cultivar development program. Of the evaluated $F$. virginiana accessions, NC 95-19-1, JP 95-1-1, CFRA 0982, NC 96-5-3, and RH 30 fruit were highest in antioxidant capacity and should prove useful toward development of strawberry cultivars with high antioxidant capacities.
\end{abstract}

Antioxidants are compounds that can delay or inhibit the oxidation of lipid or other molecules by inhibiting oxidizing chain reactions and they play an important role in health protection (Velioglu et al., 1998). In addition to being rich in folate, potassium, and fiber, fruit of the cultivated strawberry $(F . \times$ ananassa $)$ are a good source of a variety of natural antioxidants (Heinonen et al., 1998; Wang et al., 1996). Antioxidants in strawberry fruit include vitamin $\mathrm{C}$ and phenolic compounds such as phenolic acids and flavonoids, including flavonols and anthocyanins.

Important phenolic acids in strawberries are the ellagitannins and ellagic acid glucosides, which break down to pure ellagic acid, also present in the fruit (Cerdá et al., 2005). Ellagic acid is valuable to human health because it is antimutagenic and has anticarcinogenic activity against chemical-induced cancers (Okuda et al., 1989). Ellagitannins in strawberries are primarily

Received for publication 12 Dec. 2006. Accepted for publication 2 Apr. 2007. Mention of trade names or commercial products in this publication is solely for the purpose of providing specific information and does not imply recommendation or endorsement by the U.S. Department of Agriculture.

We thank Mr. Sam Garrett for propagating the plants for testing, Mr. John Enns for establishing and maintaining the strawberry field and harvesting fruit, Ms. Sue Kim for technical assistance, and Drs. John Hartung, Kim E. Hummer, James Shieh, Peter Toivonen, and the anonymous reviewers for their helpful comments.

${ }^{1}$ Corresponding author. E-mail: wangs@ba.ars.usda.gov. located in the achenes (Maas et al., 1991). The ellagic acid, glucosides, and pure ellagic acid are present in the red fleshy receptacle. Ellagic acid in pure form is poorly absorbed through the bowel and is mostly biologically unavailable whereas the ellagitannins and ellagic acid glucosides are easily available for absorption in mammalian systems (Okuda et al., 1989). In general, the content of ellagic acid glucoside of strawberry cultivars is higher than that of ellagic acid (Cerdá et al., 2005; Daniel et al., 1989).

Beneficial effects of flavonoids have been described for diabetes mellitus, allergies, cancer, viral infections, headache, stomach and duodenal ulcers, paradentosis, and inflammatory diseases (Kuehnau, 1976). Flavonoids in strawberry include the flavonols quercetin and kaempferol (Wang and Zheng, 2001). These and other polyphenols play a protective role in carcinogenesis by reducing the bioavailability of carcinogens (Starvic et al., 1992). Clegg and Morton (1968) reported that, of the flavonols, quercetin had the greatest antioxidant activity, followed by dihydroquercetin $>$ kaempferol $>$ quercitrin $>$ chlorogenic acid $=$ p-coumaric acid.

The anthocyanins are a group of flavonoids with exceptionally good scavenging activities. Pelargonidin-based anthocyanins such as pelargonidin 3-glucoside, pelargonidin 3-rutinoside, and pelargonidin 3-glucoside-succinate are the predominant anthocyanins in cultivated strawberry fruit (Gil et al., 1997; Wang and Zheng, 2001). Strawberry fruit generally 
contain much lower levels of cyanidin-based anthocyanins, cyanidin 3-glucoside and cyanidin 3-glucoside-succinate, than pelargonidin-based anthocyanins (Gil et al., 1997; Wang and Zheng, 2001). These anthocyanin compounds have shown protection against harmful free radicals and have been associated with lower incidence and mortality rates of cancer and heart disease in addition to a number of other health benefits (Ames et al., 1993; Dragsted et al., 1993; Velioglu et al., 1998; Wang et al., 1996). Antioxidant efficacy in preventing oxidation of human low-density lipoprotein among anthocyanins is as follows: delphinidin $>$ cyanidin $>$ malvidin $>$ pelargonidin (Satué-Gracia et al., 1997).

The levels of antioxidants and antioxidant capacity in strawberry extracts from whole fruits vary considerably among genotypes (Wang and Lin, 2000; Zheng and Wang, 2003). This may be true partly because the cultivated strawberry $(F$. ×ananassa $)$ is a hybrid of two very different wild species (Darrow, 1966). Accessions of the progenitor species are valued by strawberry breeders as sources of novel traits, especially pest resistance and abiotic stress tolerance. Because strawberry is a relatively new crop, dating to the $1700 \mathrm{~s}$ (Darrow, 1966), as few as three backcrosses can yield selections of cultivar quality (J.F. Hancock, pers. comm.). Therefore, if found to be of value in improving antioxidant capacity or the balance of specific phenolic compounds, accessions from these progenitor species could be readily incorporated into a strawberry breeding program.

No accession from either of the progenitor species has been evaluated for antioxidant capacity or levels of phenolic compounds. A core subset of the Fragaria L. collection maintained at the U.S. Department of Agriculture National Clonal Repository, Corvallis, OR, has been constructed to contain a group of native $F$. virginiana and $F$. chiloensis thought to be of value to strawberry improvement. This core subset is being characterized for many horticultural traits useful to breeders (Hancock et al., 2001a, b), including resistance to black root rot, common foliar diseases, and nematodes (Hancock et al., 2001b, 2002; Pinkerton and Finn, 2005), but not for antioxidant activity.
There is some antioxidant information on another wild strawberry species, $F$. vesca $\mathrm{L}$. This species is generally considered to be a progenitor of the genome of $F$. virginiana and $F$. chiloensis, and therefore $F$. ×ananassa. Sondheimer and Karash (1956) showed that the major pigments of $F$. vesca are the anthocyanins pelargonidin 3-monoglucoside and cyanidin 3-monoglucoside, and that the ratio of pelargonidin 3-glucoside to cyanidin 3-glucoside for this species was much lower (1 pelargonidin 3-glucoside : 1 cyanidin 3-glucoside) than for cultivated strawberries (1 pelargonidin 3-glucoside : 0.05 cyanidin 3-glucoside).

The objectives of this study are 1) to evaluate the antioxidant contents and antioxidant activities in representatives of $F$. virginiana and $F$. chiloensis in comparison with representatives of the cultivated strawberry species ( $F$. ×ananassa), 2) to determine which strawberry compounds are more closely correlated with antioxidant capacity among these three species, and 3) to identify wild strawberry genotypes with high antioxidant activity and bioactive compounds for use in cultivar development.

\section{Materials and Methods}

Genotypes EVALUATED. Nineteen genotypes of three strawberry species ( $F$. chiloensis, $F$. virginiana, and $F$. ×ananassa) (Table 1) were used in this study. Most of the accessions of wild strawberry, and one $F$. ×ananassa, were chosen because they are included in the core subset described by Hancock et al., (2002). Others were chosen based on past knowledge of their ability to thrive and produce fruit at Beltsville, MD. Three $F$. chiloensis accessions and $13 F$. virginiana accessions were selected. The $F$. ×ananassa cultivar, Allstar, was selected for its relatively low antioxidant capacity, whereas 'Ovation' was selected for its relatively high antioxidant capacity among cultivars from the U.S. Department of Agriculture, Agricultural Research Service strawberry breeding program at Beltsville, MD (Lewers et al., 2004).

Table 1. Fragaria (strawberry) cultivars, selections, and wild genotypes grown on the north farm of the Henry A. Wallace Agricultural Research Center at Beltsville, MD, and evaluated for antioxidant activity, total phenolics, anthocyanin, and flavonoid content.

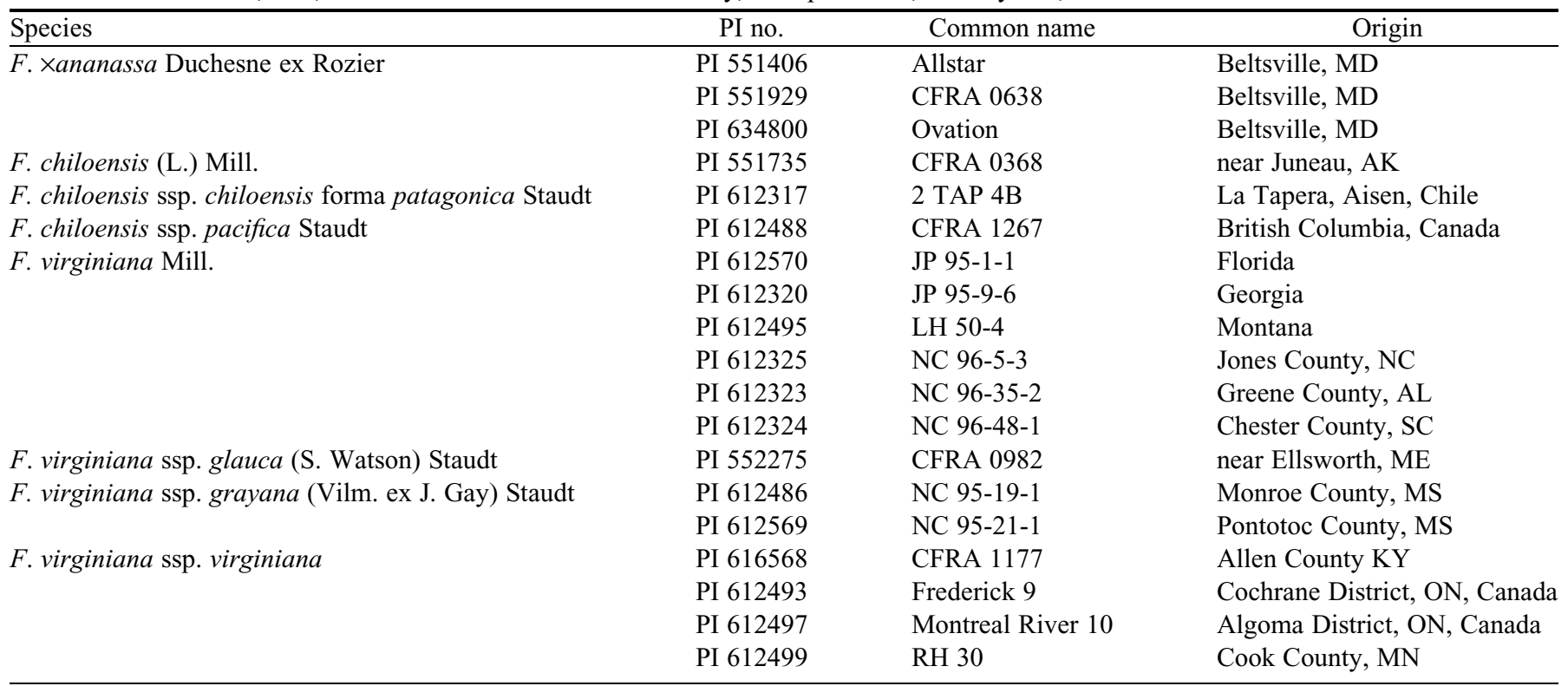


EXPERIMENTAL DESIGN, FRUIT PRODUCTION, HARVEST, AND PROCESSING. The 19 strawberry genotypes were grown on the north farm of the Henry A. Wallace Agricultural Research Center at Beltsville, MD, using the advanced matted row production system (Black et al., 2002). For each of 2 years, genotypes were randomly assigned to field plots in two blocks; each genotype was represented once in each block. Plots were harvested individually. The fruits were hand harvested at a ripe stage; sorted to eliminate damaged, shriveled, and unripe fruit; and selected for uniform size and color. The fruit harvested from two plots of any genotype were kept separate for chemical analyses. From fruit of each plot, undamaged berries were sorted into three subsamples for separate analysis, frozen in liquid nitrogen, and then stored at $-80^{\circ} \mathrm{C}$ until they were used for assays. The three subsamples were analyzed separately. After chemical analyses, the means of the subsamples were averaged to represent the fruit from each plot.

OXYGEN RADICAL ABSORBANCE CAPACITY (ORAC) ASSAY. The ORAC assay was carried out according to Huang et al. (2002) using a high-throughput instrument platform consisting of a robotic eight-channel liquid handling system. A microplate fluorescence reader (FL800; Bio-Tek Instruments, Winooski, VT) was used with fluorescence filters for an excitation wavelength of $485 \pm 20 \mathrm{~nm}$ and an emission wavelength of $530 \pm 25 \mathrm{~nm}$. The plate reader was controlled by software (KC4 3.0 revision 29; Bio-Tek Instruments). Sample dilution was accomplished using a Precision 2000 automatic pipetting system managed by Precision power software (version 1.0; Bio-Tek Instruments, Inc.). The ORAC values were determined by calculating the net area under the curve (AUC) of the standards and samples (Huang et al., 2002). The standard curve was obtained by plotting Trolox concentrations against the average net AUC of the two measurements for each concentration. Final ORAC values were calculated using the regression equation between Trolox concentration and the net AUC, and were expressed as micromole Trolox equivalents per gram fresh weight (Huang et al., 2002).

Total ANTHOCYANIN AND TOTAL PHENOLIC CONTENT. Strawberries were extracted with $80 \%$ acetone containing $0.2 \%$ formic acid using a Polytron homogenizer (Brinkmann Instruments, Westbury, NY). The homogenized samples from the acetone extracts were then centrifuged at $14,000 g_{\mathrm{n}}$ for $20 \mathrm{~min}$ at $4{ }^{\circ} \mathrm{C}$. The supernatants were transferred to vials, stored at $-80{ }^{\circ} \mathrm{C}$, and were later used for determination of total anthocyanins and total soluble phenolics.

Total anthocyanin contents in strawberry extract were determined using the $\mathrm{pH}$ differential method (Cheng and Breen, 1991). Absorbance was measured in a spectrophotometer (UV160; Shimadzu Scientific Instruments, Columbia, MD) at 510 $\mathrm{nm}$ and $700 \mathrm{~nm}$ in buffers at a $\mathrm{pH}$ of 1.0 and 4.5, using $\mathrm{A}=$ $\left[\left(A_{510}-A_{700}\right)_{\mathrm{pH} 1.0}\left(A_{510}-A_{700}\right)_{\mathrm{pH}} 4.5\right]$ with a molar extinction coefficient of pelargonidin-3-glucoside $(22,400)$ for strawberry fruit juices. Results were expressed as milligrams of pelargonidin-3-glucoside equivalent, in the strawberry extract, per $100 \mathrm{~g}$ fresh weight.

Total soluble phenolics in the fruit extract were determined with Folin-Ciocalteu reagent by the method of Slinkard and Singleton (1997) using gallic acid as a standard. Results were expressed as milligrams gallic acid equivalent, in the strawberry extract, per $100 \mathrm{~g}$ fresh weight.

High-PERFORMANCE LIQUID CHROMATOGRAPHY (HPLC) ANALYSIS OF STRAWBERRY ANTHOCYANINS AND PHENOLIC
COMPOUNDS. High performance liquid chromatography was used to separate and determine individual anthocyanins and phenolic compounds in strawberry tissue samples. Fruit samples of $5 \mathrm{~g}$ were extracted twice with $15 \mathrm{~mL}$ acetone using a Polytron (Brinkmann Instruments) for $1 \mathrm{~min}$. Extracts $(30 \mathrm{~mL})$ were combined and concentrated to $1 \mathrm{~mL}$ using a Buchler Evapomix (Buchler Instruments, Fort Lee, NJ) in a water bath at $35{ }^{\circ} \mathrm{C}$. The concentrated sample was dissolved in $10 \mathrm{~mL}$ acidified water (3\% v/v of formic acid) and then passed through a $\mathrm{C}_{18}$ Sep-Pak cartridge (Waters Corp., Milford, MA), which was previously activated with methanol followed by water and $3 \%$ aqueous formic acid. Anthocyanins and other phenolics were adsorbed onto the column whereas sugars, acids, and other water-soluble compounds were eluted with $10 \mathrm{~mL} \mathrm{3 \%}$ aqueous formic acid. The anthocyanins and other phenolics were then recovered with $2.0 \mathrm{~mL}$ acidified methanol containing $3 \%$ formic acid. The methanolic extract was passed through a 0.45- $\mu \mathrm{m}$ membrane filter (Millipore, MSI, Westboro, MA), and $20 \mu \mathrm{L}$ was analyzed by HPLC. The samples were analyzed using a Waters HPLC system equipped with two pumps (600 E system controller; Waters Corp.) coupled with a photodiode array detector (990 Series; Waters Corp.). Samples were injected at ambient temperature $\left(20^{\circ} \mathrm{C}\right)$ onto a reverse-phase NOVA-PAK $\mathrm{C}_{18}$ column $(150 \times 3.9 \mathrm{~mm}$; particle size, $4 \mu \mathrm{m})$ with a guard column (NOVA-PAK $\mathrm{C}_{18} ; 20 \times 3.9 \mathrm{~mm}$; particle size, $4 \mu \mathrm{m}$; Sentry guard holder universal; Waters Corp.). The mobile phase was acidified water containing $2.5 \%$ formic acid (A) and acetonitrile (B) in a linear gradient from 5\% to $20 \% \mathrm{~B}$ in the first $15 \mathrm{~min}$, followed by a linear gradient from $20 \%$ to $30 \% \mathrm{~B}$ for $5 \mathrm{~min}$, then an isocratic mixture for $5 \mathrm{~min}$, followed by a linear gradient from $30 \%$ to $90 \%$ B for $5 \mathrm{~min}$, then an isocratic mixture for $2 \mathrm{~min}$ before returning to the initial conditions. The flow rate was $1.0 \mathrm{~mL} \cdot \mathrm{min}^{-1}$ and the wavelengths of detection were set at 320,350 , and $510 \mathrm{~nm}$. Scanning between 240 and $550 \mathrm{~nm}$ was performed and data were collected using the Waters 990 3-D chromatography data system. Retention times and spectra were compared with pure standards. Results were expressed as microgram per gram fresh weight of phenolic acid or flavonol or expressed as microgram per gram fresh weight of cyanidin 3-glucoside or pelargonidin 3- glucoside.

Statistical analysis. To determine differences between genotypes and genotype-by-year interactions, an analysis of variance was done using SAS (version 9.1.3; SAS Institute, Cary, NC). Genotypes and related interaction effects were considered fixed. Some of the genotypes were not tested in both years and some of the plots did not produce sufficient fruit, resulting in missing data. Therefore, the data were analyzed using the proc mixed command and the "pdmix800" subroutine. This analysis fits the data to a model and reports estimated means, based on the model. The model used included genotype, year, and genotype-by-year interactions as its sources of variance. Differences at $P=0.05$ were considered significant. Because the proc mixed command does not generate estimates of mean squares for the sources of variance contributing to the model, the data also were analyzed using the proc glm command, and mean squares were reported from type III sums of squares.

To determine differences between species, and speciesby-year interactions, a second analysis of variance was done using the same program, but this time the model included species, year, and species-by-year interactions as the sources 
Table 2. Antioxidant activity, anthocyanin content, and total phenolic content in Fragaria (strawberry) cultivars, selections, and wild genotypes.

\begin{tabular}{|c|c|c|c|c|c|c|c|c|c|c|}
\hline$\frac{\text { Genotype }}{F . \text { virginiana }}$ & $\frac{\text { Year }}{\text { Average }}$ & \multicolumn{3}{|c|}{$\begin{array}{c}\text { ORAC } \\
{\left[\mathrm{TE}\left(\mu \mathrm{mol} \cdot \mathrm{g}^{-1} \mathrm{FW}\right]^{\mathrm{z}}\right.}\end{array}$} & \multicolumn{3}{|c|}{$\begin{array}{c}\text { Anthocyanin } \\
\left(\mathrm{mg} \cdot 100 \mathrm{~g}^{-1} \mathrm{FW}\right)^{\mathrm{y}}\end{array}$} & \multicolumn{3}{|c|}{$\begin{array}{c}\text { Total phenolic } \\
\left(\mathrm{mg} \cdot 100 \mathrm{~g}^{-1} \mathrm{FW}\right)^{\mathrm{x}}\end{array}$} \\
\hline F. chiloensis & Average & & 35.94 & $\mathrm{~b}$ & & 44.65 & $\mathrm{~b}$ & & 160.06 & $\mathrm{~b}$ \\
\hline Significance & & $\mathrm{df}$ & Mean square & & $\mathrm{df}$ & Mean square & & $\mathrm{df}$ & Mean square & \\
\hline Species & & 2 & 704.9 & $* *$ & 2 & 836.5 & $* *$ & 2 & $19,297.5$ & $* *$ \\
\hline Year & & 1 & 56.6 & NS & 1 & 299.8 & $*$ & 1 & $2,245.8$ & $*$ \\
\hline \multicolumn{11}{|l|}{ F. $\times$ ananassa } \\
\hline Allstar & 2004 & & - & - & & - & - & & - & - \\
\hline Allstar & 2005 & & 26.19 & $\mathrm{~m}^{d}$ & & 40.50 & nop & & 123.24 & $\mathrm{~m}$ \\
\hline CFRA 0638 & 2004 & & - & - & & - & - & & - & - \\
\hline CFRA 0638 & 2005 & & 32.06 & $\mathrm{jklm}$ & & 48.69 & $\mathrm{jklm}$ & & 159.99 & ijkl \\
\hline Ovation & 2004 & & 33.69 & $\mathrm{jklm}$ & & 45.81 & $\mathrm{klmn}$ & & 137.65 & $\mathrm{~lm}$ \\
\hline 2 TAP 4B & 2004 & & 38.97 & fghijk & & 44.21 & $\operatorname{lmn}$ & & 170.90 & hi \\
\hline 2 TAP $4 \mathrm{~B}$ & 2005 & & 42.54 & defghi & & 56.58 & efgh & & 193.03 & efgh \\
\hline \multicolumn{11}{|c|}{ F. chiloensis ssp. pacifica } \\
\hline CFRA 1267 & 2004 & & 32.03 & $\mathrm{klm}$ & & 38.22 & op & & 139.58 & $\operatorname{lm}$ \\
\hline CFRA 1267 & 2005 & & 37.12 & ijkl & & 50.73 & $\mathrm{ijk}$ & & 167.75 & $\mathrm{ij}$ \\
\hline \multicolumn{11}{|l|}{ F. virginiana } \\
\hline JP 95-1-1 & 2004 & & 46.12 & defg & & 55.74 & fghi & & 219.96 & bcd \\
\hline JP 95-1-1 & 2005 & & 48.96 & $\mathrm{~cd}$ & & 57.33 & efg & & 223.10 & $\mathrm{bc}$ \\
\hline JP 95-9-6 & 2004 & & 42.49 & defghij & & 46.67 & jklmn & & 192.05 & defghi \\
\hline JP 95-9-6 & 2005 & & 46.06 & defg & & 61.17 & def & & 233.69 & $\mathrm{~b}$ \\
\hline LH 50-4 & 2004 & & 49.26 & bcd & & 63.37 & $\mathrm{~cd}$ & & 219.55 & bcd \\
\hline LH 50-4 & 2005 & & 43.22 & defghi & & 58.30 & defg & & 209.67 & bcde \\
\hline CFRA 0982 & 2005 & & 61.69 & $\mathrm{a}$ & & 74.83 & A & & 259.98 & $\mathrm{a}$ \\
\hline \multicolumn{11}{|c|}{ F. virginiana ssp. grayana } \\
\hline NC 95-19-1 & 2004 & & 56.95 & $\mathrm{abc}$ & & 73.59 & $a b$ & & 233.36 & $\mathrm{~b}$ \\
\hline NC 95-19-1 & 2005 & & 45.39 & defgh & & 61.67 & de & & 257.29 & a \\
\hline NC 95-21-1 & 2004 & & 30.38 & $\operatorname{lm}$ & & 33.90 & $\mathrm{P}$ & & 169.11 & hij \\
\hline NC 95-21-1 & 2005 & & 42.25 & defghi & & 57.58 & efg & & 198.99 & cdefg \\
\hline \multicolumn{11}{|c|}{ F. virginiana $\mathrm{ssp}$. virginiana } \\
\hline CFRA 1177 & 2004 & & 45.22 & defghi & & 48.47 & $\mathrm{jklmn}$ & & 206.44 & bcdef \\
\hline CFRA 1177 & 2005 & & - & - & & - & - & & - & - \\
\hline Frederick 9 & 2004 & & 34.93 & ijklm & & 45.53 & klmn & & 170.83 & ghijk \\
\hline Frederick 9 & 2005 & & 43.96 & defghi & & 57.02 & efgh & & 199.52 & cdefg \\
\hline Montreal River 10 & 2004 & & 38.01 & hijkl & & 52.70 & ghij & & 182.67 & fghi \\
\hline Montreal River 10 & 2005 & & 45.80 & defgh & & 56.75 & efgh & & 213.06 & bcde \\
\hline RH 30 & 2004 & & - & - & & - & - & & - & - \\
\hline RH 30 & 2005 & & 47.85 & de & & 62.07 & de & & 218.87 & bcd \\
\hline Significance & & $\mathrm{df}$ & Mean square & & $\mathrm{df}$ & Mean square & & $\mathrm{df}$ & Mean square & \\
\hline Genotype & & 18 & 166.6 & $* *$ & 18 & 214.5 & $* *$ & 18 & 3337.4 & $* *$ \\
\hline Year & & 1 & 137.0 & $* *$ & 1 & 627.7 & $* *$ & 1 & 5428.7 & $* *$ \\
\hline Genotype $\times$ year & & 12 & 42.3 & $*$ & 12 & 80.8 & $* *$ & 12 & 288.4 & NS \\
\hline Error & & 26 & 15.2 & & 26 & 7.7 & & 26 & 140.4 & \\
\hline
\end{tabular}

${ }^{\mathrm{z}}$ Data expressed as micromoles of Trolox (TE) equivalents per gram fresh weight (FW).

${ }^{y}$ Data expressed as milligrams of cyanidin 3-glucoside equivalents per $100 \mathrm{~g} \mathrm{FW}$.

${ }^{\mathrm{x}}$ Data expressed as milligrams of gallic acid equivalents per $100 \mathrm{~g} \mathrm{FW}$.

"Mean within same column followed different letter are significantly different at $P=0.05$.

NS, ${ }^{*}, *$ Nonsignificant, significant at $P=0.05$ and $P=0.01$ respectively. 
of variance. Species and related interaction effects were considered fixed. A third analysis was done that was identical to the second, except only three $F$. virginiana genotypes were included to confirm the analysis was not biased as a result of having 13 representatives of $F$. virginiana compared with only three representatives of either $F$. chiloensis or $F$. ×ananassa. The three genotypes selected were those with the lowest ORAC means according to the first analysis: LH 50-4, NC 96-35-2, and Frederick 9.

To determine which strawberry compounds are most closely correlated with antioxidant activity among these three species, correlation coefficients were calculated based on genotype mean averaged across plots within year for the antioxidant activities versus the concentration of each of the compounds measured. Correlation coefficients were calculated using Excel 2003 (Microsoft Corp., Redmond, WA), and are reported as $R^{2}$ values.

\section{Results and Discussion}

Differences Among SPECIES. Fruit of the $F$. virginiana accessions tested had significantly higher $(P \leq 0.05)$ antioxidant capacity, total phenolics, and total anthocyanins than did fruit of the $F$. chiloensis and $F$. ×ananassa accessions evaluated (Table 2). Levels of the phenolic acid, ellagic acid, were similar among representatives of the three species (Table 3 ), but levels of several flavonoids (the flavonols and anthocyanins) were significantly higher in fruit of the $F$. virginiana accessions compared with fruit of either the $F$. chiloensis or $F$. ×ananassa accessions evaluated (Table 4$)$.

Of the anthocyanins, the levels of cyanidin 3-glucosidesuccinate were highest in fruit of the $13 F$. virginiana accessions, although not significantly different $(P \leq 0.05)$ from those of the three $F$. chiloensis accessions evaluated (Table 4). Differences between the three species in the levels of this anthocyanin were not significant when only the three $F$. virginiana genotypes lowest in antioxidant capacity were used in the analysis. Fruits of the $13 F$. virginiana accessions also had the highest levels of the anthocyanin pelargonidin 3-glucoside, although not significantly different from those in the three $F$. ×ananassa accessions tested. As has previously been reported with cultivated $F$. ×ananassa (Gil et al., 1997; Wang and Zheng, 2001), the levels, in accessions tested from both the wild progenitor species, of cyanidin 3-glucoside and pelargonidin 3-glucoside were higher than their succinate counterparts, and the pelargonidin-based anthocyanins were predominant over the cyanidin-based anthocyanins. As with $F$. vesca (Sondheimer and Karash, 1956), the ratios of pelargonidin 3-glucosate to cyanidin 3-glucosate were lower in fruits of both $F$. virginiana and $F$. chiloensis accessions tested compared with $F$. ×ananassa accessions tested, although it is not appropriate to test the significance of the differences between the ratios for the three species (Table 4). The lower ratios are thought to be desirable because cyanidin 3-glucoside has greater antioxidant capacity than that of pelargonidin 3-glucoside (Satué-Gracia et al., 1997).

Also supporting previous findings (Wang and Zheng, 2001) on strawberry fruit flavonols, the levels of quercetin-based flavonols were higher than those of the other flavonols present in strawberry fruit (Table 3). Once again, fruit of the $13 \mathrm{~F}$. virginiana accessions tested contained higher levels of both these quercetin-based compounds and another flavonol, kaemp- ferol 3-rutinoside. However, differences between the three species in the levels of the quercetin-based compounds were not significant when only the three $F$. virginiana genotypes lowest in antioxidant capacity were used in the analysis.

Correlations between antioxidant CAPACity AND PHENOLIC COMPOUNDS. To determine which phenolic compounds were contributing the most to antioxidant capacity in the fruit of the wild strawberry, correlation coefficients were calculated between antioxidant capacity and the levels of each of the compounds tested. As with previous reports (Wang and Lin, 2000), significant correlations were found between antioxidant capacity and both total phenolics $\left(R^{2}=0.8093\right)$ and total anthocyanins $\left(R^{2}=0.8037\right)$. However, in this study, there was no correlation between antioxidant activity and any of the individual compounds tested. A study of the same genotypes found a strong positive correlation $\left(R^{2}=0.812\right)$ between antioxidant capacity and vitamin C (S.Y. Wang, K.S. Lewers, L. Bowman, and M. Ding, unpublished).

Because ORAC was correlated only to total phenolics and total anthocyanins, any of these three measures will be useful in selecting genotypes for cultivar development. The choice of assay in different stages of selection will depend primarily on the balance of efficiency and reliability required at each stage. For example, visual selection for dark, bright fruit skin and flesh is a rapid and low-cost assay for anthocyanin levels. This may be the most efficient selection method to use on an individual plant basis in a seedling field. A more objective and quantifiable assay may be desirable for later selections from replicated evaluations at one or more locations. Previous studies have shown that antioxidant capacity, total anthocyanins, and total phenolics vary significantly in different growing environments (Wang and Lin, 2003; Wang and Zheng, 2001; Wang et al., 2002, 2003), so that it is highly desirable to make selections based on data from multiple replications and environments (years or locations). In this study, the genotype-by-year interactions for antioxidant capacity and total anthocyanins were significant, but the genotype-by-year interaction for total phenolic measurements was not (Table 2). The assays used to measure total phenolics or total anthocyanins were more simple and less expensive than the ORAC assay to measure antioxidant capacity. The high correlation with antioxidant capacity, relative efficiency, and lack of genotype-by-year interaction in this study suggests that the measurement of total phenolics may be the better assay to use for the later selection stages in a strawberry cultivar development program.

Differences among individual Genotypes. Differences among genotypes were significant for each of the specific phenolic compounds measured (Tables 3 and 4). In determining differences among genotypes for antioxidant capacity and levels of the various phenolic compounds, significant genotype-by-year interactions were observed for all traits except total phenolics, so genotypic means are reported for each year (Tables 2-4).

The cultivar Ovation was tested with other $F$. ×ananassa genotypes only in 2005, and its higher ORAC value was not significantly different from that of the other two $F$. ×ananassa genotypes when tested in this group, even though Lewers et al. (2004) had compared it with several other $F$. Xananassa cultivars and selections and found it to be significantly higher in antioxidant capacity. Genotypes with significantly higher ORAC values than that of 'Ovation' in both 2004 and 2005 were NC 95-19-1, JP 95-1-1, and NC 96-48-1. In 2004, CFRA 
Table 3. Content of phenolic acids (ellagic acid) and flavonols (quercetin 3-glucoside plus quercetin 3-glucuronide, kaempferol 3-glucoside, kaempferol 3-rutinoside, and p-coumaryl-glucose) in fruit of Fragaria (strawberry) cultivars, selections, and wild genotypes.

\begin{tabular}{|c|c|c|c|c|c|c|c|c|c|c|c|c|c|c|c|c|}
\hline \multirow{2}{*}{$\frac{\text { Genotype }}{F . \text { virginiana }}$} & \multirow{2}{*}{$\frac{\text { Year }}{\text { Average }}$} & \multicolumn{9}{|c|}{$\begin{array}{l}\text { Quercetin 3-glucoside } \\
\text { plus quercetin }\end{array}$} & & \multicolumn{4}{|c|}{ Kaempferol } & $\begin{array}{l}\text { glucose } \\
(W)^{x}\end{array}$ \\
\hline & & & 22.32 & & & 78.07 & $\mathrm{a}^{\mathrm{w}}$ & & 11.23 & & & 19.82 & $\mathrm{a}$ & & 20.12 & \\
\hline F. chiloensis & Average & & 34.98 & & & 48.94 & $\mathrm{~b}$ & & 6.53 & & & 11.98 & $\mathrm{~b}$ & & 24.53 & \\
\hline$F . \times$ ananassa & Average & & 19.88 & & & 40.81 & $\mathrm{~b}$ & & 8.37 & & & 10.94 & $\mathrm{~b}$ & & 11.42 & \\
\hline Significance & & df & $\begin{array}{l}\text { Mean } \\
\text { square }\end{array}$ & & df & $\begin{array}{l}\text { Mean } \\
\text { square }\end{array}$ & & df & $\begin{array}{l}\text { Mean } \\
\text { square }\end{array}$ & & df & $\begin{array}{l}\text { Mean } \\
\text { square }\end{array}$ & & df & $\begin{array}{l}\text { Mean } \\
\text { square }\end{array}$ & \\
\hline Species & & 2 & 309.6 & NS & 2 & $4,130.6$ & $* *$ & 2 & 99.6 & NS & 2 & 367.8 & $*$ & 2 & 256.2 & NS \\
\hline Year & & 1 & 168.0 & NS & 1 & $2,129.3$ & $*$ & 1 & 35.0 & NS & 1 & 665.8 & $*$ & 1 & 112.5 & NS \\
\hline Species $\times$ year & & 2 & 24.3 & NS & 2 & 45.8 & NS & 2 & 50.1 & NS & 2 & 31.4 & NS & 2 & 269.0 & NS \\
\hline Error & & 31 & 188.0 & & 40 & 475.4 & & 48 & 49.7 & & 47 & 104.4 & & 46 & 235.5 & \\
\hline \multicolumn{17}{|l|}{ F. $\times$ ananassa } \\
\hline Allstar & 2004 & & - & & & - & - & & - & - & & - & - & & - & - \\
\hline Allstar & 2005 & & 19.15 & defg & & 46.10 & ghij & & 3.53 & ijklmn & & 17.11 & defghij & & 15.12 & efghij \\
\hline CFRA 0638 & 2004 & & - & - & & - & - & & - & - & & - & - & & - & - \\
\hline CFRA 0638 & 2005 & & - & - & & - & - & & - & - & & 24.72 & bcde & & - & - \\
\hline Ovation & 2004 & & 24.64 & de & & 28.27 & $\mathrm{j}$ & & 10.64 & defgh & & 5.15 & $\mathrm{jk}$ & & 8.30 & $\mathrm{j}$ \\
\hline Ovation & 2005 & & 11.10 & fg & & 60.59 & defghi & & 9.56 & efghi & & 8.40 & fghijk & & 13.95 & efghij \\
\hline \multicolumn{17}{|l|}{ F. chiloensis } \\
\hline CFRA 0368 & 2004 & & - & - & & 70.65 & cdefg & & 1.47 & $\mathrm{n}$ & & 5.86 & $\mathrm{jk}$ & & 10.67 & hij \\
\hline CFRA 0368 & 2005 & & - & - & & - & - & & 16.34 & $\mathrm{bc}$ & & 13.71 & defghijk & & 41.02 & $\mathrm{c}$ \\
\hline \multicolumn{17}{|c|}{ F. chiloensis ssp. chiloensis forma patagonica } \\
\hline 2 TAP 4B & 2004 & & 38.32 & bc & & 2.98 & $\mathrm{k}$ & & 6.83 & hijklm & & 3.28 & $\mathrm{k}$ & & 56.98 & $\mathrm{~b}$ \\
\hline 2 TAP 4B & 2005 & & 31.64 & $\mathrm{~cd}$ & & 56.15 & fghi & & 7.57 & ghijk & & 17.89 & defgh & & 18.99 & def \\
\hline \multicolumn{17}{|c|}{ F. chiloensis ssp. pacifica } \\
\hline CFRA 1267 & 2004 & & - & - & & 51.58 & ghi & & 2.59 & $\operatorname{lmn}$ & & 9.85 & ghijk & & 12.95 & ghij \\
\hline CFRA 1267 & 2005 & & - & - & & - & - & & 8.09 & fghij & & 19.34 & defg & & 16.02 & efgh \\
\hline \multicolumn{17}{|l|}{ F. virginiana } \\
\hline JP 95-1-1 & 2004 & & 14.71 & efg & & 70.50 & cdefg & & 15.76 & $\mathrm{~b}$ & & 30.86 & $\mathrm{bc}$ & & 16.27 & efgh \\
\hline JP 95-1-1 & 2005 & & 15.76 & efg & & 86.30 & bcd & & 16.09 & bcd & & 34.63 & $a b c$ & & 14.45 & efghij \\
\hline JP 95-9-6 & 2004 & & - & - & & 85.66 & bcde & & 8.59 & efghijk & & 4.15 & $\mathrm{jk}$ & & 7.47 & $\mathrm{ij}$ \\
\hline JP 95-9-6 & 2005 & & - & - & & 139.91 & $\mathrm{a}$ & & 10.13 & efgh & & 24.04 & $\mathrm{~cd}$ & & 25.57 & d \\
\hline LH 50-4 & 2004 & & 15.86 & efg & & 76.01 & bcdef & & 11.38 & bcdefg & & 31.22 & $\mathrm{bc}$ & & 13.16 & fghij \\
\hline LH 50-4 & 2005 & & 13.34 & fg & & 88.76 & $\mathrm{bc}$ & & 3.91 & jklmn & & 36.03 & $\mathrm{ab}$ & & 12.09 & ghij \\
\hline NC 96-5-3 & 2004 & & - & - & & - & - & & - & - & & - & - & & - & - \\
\hline NC 96-5-3 & 2005 & & 6.21 & g & & 78.47 & bcde & & 24.45 & $\mathrm{a}$ & & - & - & & 51.71 & $\mathrm{~b}$ \\
\hline NC 96-35-2 & 2004 & & 55.59 & $\mathrm{a}$ & & 41.47 & $\mathrm{ij}$ & & 0.58 & $\mathrm{n}$ & & 14.50 & defghij & & 13.92 & efghij \\
\hline NC 96-35-2 & 2005 & & 31.41 & $\mathrm{~cd}$ & & 75.92 & bcdef & & 25.50 & $\mathrm{a}$ & & 5.11 & $\mathrm{jk}$ & & 12.78 & ghij \\
\hline NC 96-48-1 & 2004 & & 19.96 & ef & & 79.76 & bcde & & 3.68 & jklmn & & 7.21 & $\mathrm{ijk}$ & & 16.44 & efgh \\
\hline NC 96-48-1 & 2005 & & 36.80 & bc & & 76.94 & bcde & & 11.09 & cdefgh & & 6.51 & $\mathrm{jk}$ & & 12.84 & ghij \\
\hline F. virginiana ssp. gla & auca & & & & & & & & & & & & & & & \\
\hline CFRA 0982 & 2004 & & - & - & & - & - & & - & - & & - & - & & - & - \\
\hline CFRA 0982 & 2005 & & - & - & & - & - & & 22.35 & $\mathrm{a}$ & & 16.66 & defghi & & 71.49 & $\mathrm{a}$ \\
\hline F. virginiana ssp. gra & ayana & & & & & & & & & & & & & & & \\
\hline NC 95-19-1 & 2004 & & 18.97 & efh & & 93.92 & $\mathrm{~b}$ & & 13.76 & bcde & & 17.56 & defgh & & 8.83 & $\mathrm{ij}$ \\
\hline NC 95-19-1 & 2005 & & 17.98 & efg & & 96.30 & $\mathrm{~b}$ & & 13.39 & bcdef & & 22.63 & cdef & & - & - \\
\hline NC 95-21-1 & 2004 & & - & - & & 60.65 & efghi & & 14.07 & bcde & & 12.40 & efghijk & & 23.92 & $\mathrm{~d}$ \\
\hline NC 95-21-1 & 2005 & & 12.68 & fg & & 85.13 & bcd & & 12.58 & bcdef & & 14.68 & defghij & & 23.83 & $\mathrm{~d}$ \\
\hline F. virginiana ssp. virg & rginiana & & & & & & & & & & & & & & & \\
\hline CFRA 1177 & 2004 & & 40.63 & bc & & 82.36 & bcde & & 8.11 & fghijkl & & 5.70 & hijk & & 7.17 & $\mathrm{j}$ \\
\hline CFRA 1177 & 2005 & & - & - & & - & - & & - & - & & - & - & & - & - \\
\hline Frederick 9 & 2004 & & 5.92 & gh & & 43.12 & hij & & 2.34 & klmn & & 13.24 & defghijk & & 15.68 & efghi \\
\hline Frederick 9 & 2005 & & 14.91 & efg & & 85.32 & bcd & & 3.32 & klmn & & 33.01 & $\mathrm{abc}$ & & 19.44 & de \\
\hline Montreal River 10 & 2004 & & 17.56 & efh & & 41.57 & $\mathrm{ij}$ & & 2.32 & $\mathrm{mn}$ & & 15.06 & defghij & & 15.27 & efgh \\
\hline Montreal River 10 & 2005 & & 49.71 & $\mathrm{ab}$ & & 71.98 & bcdefgh & & 2.72 & $\operatorname{lmn}$ & & 42.42 & $\mathrm{a}$ & & 17.05 & efg \\
\hline RH 30 & 2004 & & - & - & & - & - & & - & - & & - & - & & - & - \\
\hline
\end{tabular}


Table 3. Continued.

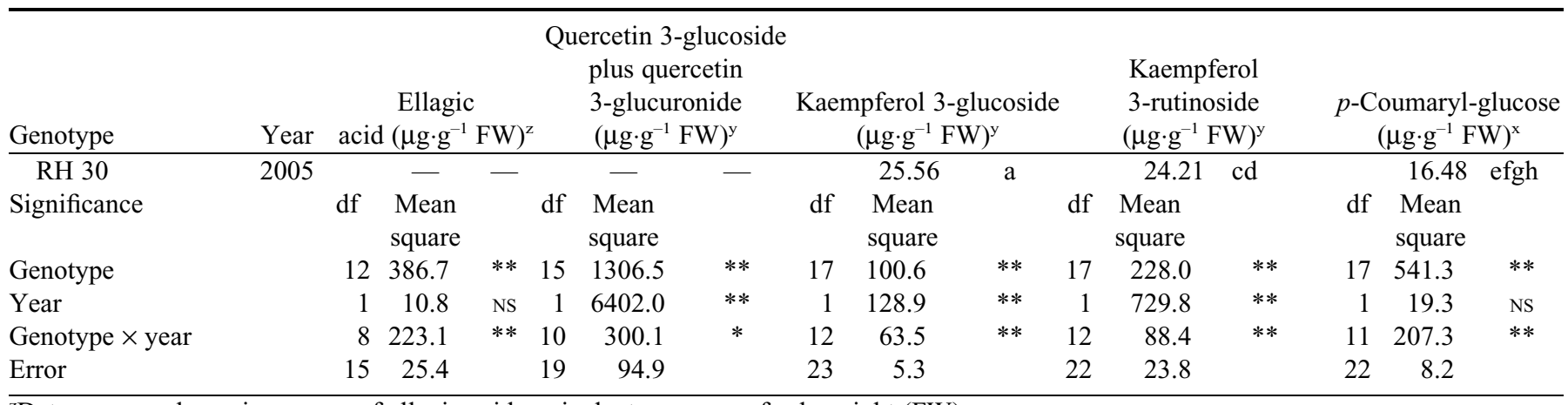

${ }^{\mathrm{z}}$ Data expressed as micrograms of ellagic acid equivalents per gram fresh weight (FW).

${ }^{y}$ Data expressed as micrograms of quercetin 3-glucoside equivalents per gram $\mathrm{FW}$.

${ }^{x}$ Data expressed as micrograms of p-coumaric acid equivalents per gram FW.

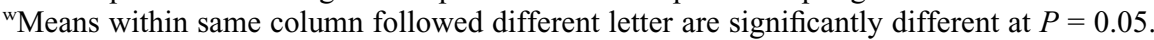

NS, ${ }^{*}, * *$ Nonsignificant, significant at $P=0.05$ and $P=0.01$ respectively.

1177 also had a significantly higher ORAC value than 'Ovation', but it was not tested in 2005. Likewise, in 2005, CFRA 0982, NC 96-5-3, and RH 30 had higher ORAC values, but were not compared with 'Ovation' in 2004. The genotype-byyear interactions affected comparisons between 'Ovation' and JP 95-9-6, NC 96-35-2, and LH 50-4. These genotypes had significantly higher ORAC values than 'Ovation' in only 1 of 2 years tested. All the genotypes with significantly higher ORAC values than 'Ovation' were $F$. virginiana genotypes.

Genotypes with significantly higher total anthocyanin content than 'Ovation' also were all $F$. virginiana (Table 2). Genotypes with higher anthocyanin content in both years were NC 95-19-1, LH 50-4, and JP 95-1-1. Also higher in 2005 but not measured in 2004 were CFRA 0982, NC 96-5-3, and RH 30. The genotype-by-year interactions affected comparisons between 'Ovation' and Montreal River 10, NC 96-48-1, JP 95-9-6, NC 96-35-2, and NC 95-21-1, which had significantly higher total anthocyanin content than 'Ovation' in only 1 of 2 years tested.

The comparisons between 'Ovation' and the other genotypes were more consistent when comparing total phenolics (Table $2)$. The only genotypes significantly lower than 'Ovation' in total phenolics were CFRA 1267 and CFRA 0368 (both F. chiloensis) in 2004 and 2005, and also the other two $F$. xananassa genotypes ('Allstar' and CFRA 0638), which were added to the comparison in 2005. All other genotypes were higher in total phenolics, although the differences for NC 9521-1, Frederick 9 (F. virginiana), and 2 TAP 4B (F. chiloensis $)$ were not significant in 2005.

The two genotypes that were compared with 'Ovation' both years and were significantly higher in antioxidant capacity, total anthocyanins, and total phenolics were the $F$. virginiana genotypes NC 95-19-1 and JP 95-1-1. In addition, these two accessions are valued as strawberry parental material as potential sources of resistance to anthracnose crown rot incited by Colletotrichum fragariae A.N. Brooks (K.S. Lewers, W.W. Turechek, S.C. Hokanson, J.L. Maas, J.F. Hancock, S. Serçe, and B.J. Smith, unpublished). JP 95-1-1 is also resistant to crown rot incited by C. gloeosporioides (Penz.) Penz. \& Sacc. in Penz. [teleomorph Glomerella cingulata (Stoneman) Spauld. \& H. Schrenk] (K.S. Lewers, W.W. Turechek, S.C. Hokanson, J.L. Maas, J.F. Hancock, S. Serçe, and B.J. Smith, unpublished) and to both the northern root knot nematode (Meloidogyne hapla Chitwood) and the root lesion nematode [Pratyenchus penetrans (Cobb) Filipjev \& Shuurmans Stekhoven] (Pinkerton and Finn, 2005). NC95-19-1, a female, is also resistant to the root knot nematode (Pinkerton and Finn, 2005), and leaf scorch, Diplocarpon earlianum (Ellis \& Everh.); tolerant to leaf blight Phomopsis obscurans (Ellis \& Everh.) Sutton and powdery mildew Sphaerotheca macularis (Wallr.:Fr.) Jacz. f.sp. fragariae Peries (Hancock et al., 2001a, b, 2002); and has very good flavor (data not shown).

Three additional $F$. virginiana genotypes were higher for all three values but were compared with 'Ovation' only in 2005. These were CFRA 0982, NC 96-5-3, and RH 30. CFRA 0982 and RH 30 also are valued because they flower more than once per year (Hancock et al., 2001b). RH 30 also is resistant to root knot nematode (Pinkerton and Finn, 2005), black root rot incited by an unknown pathogen or group of pathogens, leaf scorch, and leaf spot incited by Mycosphaerella fragariae (Tul.) Lindau (Hancock et al., 2001a). NC 96-5-3 is of interest in strawberry breeding because it is resistant to both the northern root knot nematode and the root lesion nematode (Pinkerton and Finn, 2005), plus leaf scorch and powdery mildew is tolerant to leaf blight, and has upright peduncles (Hancock et al., 2001a, b; 2002) of value in keeping flowers and fruit off the ground and away from inoculum of fruit rotting pathogens.

Fruit of the $13 F$. virginiana accessions had significantly higher $(P=0.05)$ antioxidant capacity, total phenolics, and total anthocyanins than fruit from the three $F$. chiloensis and the three $F$. ×ananassa accessions evaluated. Because we tested only a few $F$. chiloensis accessions, there may be other wild $F$. chiloensis accessions that are very high in antioxidants. In addition, high antioxidant content is a trait that can be selected for in cultivar development, so other $F$. Xananassa genotypes may have fruit containing levels of antioxidants that are higher than the three $F$. Xananassa accessions we tested, now or in the future. The best way to select these future cultivars may be to test for high total phenolics, because this was highly correlated with antioxidant capacity, was relatively efficient, and, in this study, lacked a genotype-by-year interaction. Accessions that should be valuable as parent material for developing more nutritious strawberry cultivars include NC 95-19-1, JP 95-1-1, 
Table 4. Content and ratios of the prominent anthocyanins in Fragaria (strawberry) cultivars, selections, and wild genotypes.

\begin{tabular}{|c|c|c|c|c|c|c|c|c|c|c|c|c|c|c|}
\hline \multirow{2}{*}{$\frac{\text { Genotype }}{F \cdot \text { virginiana }}$} & \multirow{2}{*}{$\frac{\text { Year }}{\text { Average }}$} & \multicolumn{3}{|c|}{$\begin{array}{c}\text { 3-glucoside } \\
{\left[\mathrm{CG}\left(\mu \mathrm{g} \cdot \mathrm{g}^{-1} \mathrm{FW}\right)\right]^{\mathrm{z}}}\end{array}$} & \multicolumn{3}{|c|}{$\begin{array}{c}\text { 3-glucoside } \\
{\left[\mathrm{PG}\left(\mu \mathrm{g} \cdot \mathrm{g}^{-1} \mathrm{FW}\right)\right]^{\mathrm{y}}}\end{array}$} & \multicolumn{3}{|c|}{$\begin{array}{c}\text { Cyanidin } \\
\text { 3-glucoside-succinate } \\
{\left[\mathrm{CG}\left(\mu \mathrm{g} \cdot \mathrm{g}^{-1} \mathrm{FW}\right)\right]^{\mathrm{z}}}\end{array}$} & \multicolumn{3}{|c|}{$\begin{array}{c}\text { Pelargonidin } \\
\text { 3- glucoside-succinate } \\
{\left[\mathrm{PG}\left(\mu \mathrm{g} \cdot \mathrm{g}^{-1} \mathrm{FW}\right)\right]^{\mathrm{y}}}\end{array}$} & \multirow{2}{*}{$\begin{array}{c}\begin{array}{c}\text { PG-to-CG } \\
\text { ratio }\end{array} \\
5.07\end{array}$} \\
\hline & & \multicolumn{3}{|c|}{105.06} & & 418.05 & $\mathrm{a}^{\mathrm{z}}$ & & 38.04 & $\mathrm{a}$ & & 98.72 & & \\
\hline F. chiloensis & Average & & 95.32 & & & 253.48 & $\mathrm{~B}$ & & 35.80 & $\mathrm{a}$ & & 85.71 & & 3.88 \\
\hline F. $\times$ ananassa & Average & & 38.01 & & & 401.20 & A & & 16.69 & $\mathrm{~b}$ & & 64.00 & & 13.41 \\
\hline Significance & & $\mathrm{df}$ & Mean square & & df & Mean square & & df & Mean square & & $\mathrm{df}$ & Mean square & & \\
\hline Species & & 2 & $9,587.5$ & NS & 2 & $116,303.8$ & ** & 2 & 970.7 & * & 2 & $2,921.7$ & NS & \\
\hline Year & & 1 & $1,711.0$ & NS & 1 & $2,338.3$ & NS & 1 & 245.0 & NS & 1 & 527.9 & NS & \\
\hline Species $\times$ year & & 2 & 62.4 & NS & 2 & $3,074.2$ & NS & 2 & 164.7 & NS & 2 & 611.2 & NS & \\
\hline Error & & 48 & $3,705.8$ & & 50 & $11,257.6$ & & 48 & 213.0 & & 48 & $3,951.7$ & & \\
\hline F. $\times$ ananassa & & & & & & & & & & & & & & \\
\hline Allstar & 2004 & & - & - & & - & - & & - & - & & - & - & - \\
\hline Allstar & 2005 & & 16.29 & $\mathrm{p}$ & & 361.48 & hijklm & & 22.11 & $\mathrm{a}$ & & 15.47 & $\operatorname{lmn}$ & 22.19 \\
\hline CFRA 0638 & 2004 & & - & - & & - & - & & - & - & & - & - & - \\
\hline CFRA 0638 & 2005 & & 87.48 & fg & & 375.79 & ghijklm & & 4.22 & $\mathrm{ijk}$ & & 36.56 & efghi & 4.30 \\
\hline Ovation & 2004 & & 30.03 & nop & & 410.79 & fghi & & 13.73 & $\mathrm{~b}$ & & 10.42 & $\mathrm{n}$ & 13.68 \\
\hline Ovation & 2005 & & 34.19 & mnop & & 437.53 & defgh & & 12.72 & $\mathrm{bc}$ & & 16.85 & klmn & 12.80 \\
\hline F. chiloensis & & & & & & & & & & & & & & \\
\hline CFRA 0368 & 2004 & & 68.25 & ghij & & 300.90 & mo & & 4.41 & $\mathrm{ij}$ & & 31.37 & hij & 4.41 \\
\hline CFRA 0368 & 2005 & & 58.77 & ijkl & & 262.00 & o & & 4.38 & hijk & & 26.16 & ijklm & 4.46 \\
\hline F. chiloensis ssp. chile & oensis for & $\operatorname{ma} p$ & patagonica & & & & & & & & & & & \\
\hline 2 TAP 4B & 2004 & & 27.75 & op & & 161.82 & $\mathrm{p}$ & & 5.85 & fg & & 44.47 & def & 5.83 \\
\hline 2 TAP 4B & 2005 & & 43.91 & klmn & & 256.51 & o & & 5.85 & fg & & 69.14 & $\mathrm{a}$ & 5.84 \\
\hline F. chiloensis ssp. paci & ifica & & & & & & & & & & & & & \\
\hline CFRA 1267 & 2004 & & 172.14 & $\mathrm{c}$ & & 262.72 & o & & 1.52 & $\mathrm{n}$ & & 20.95 & jklmn & 1.53 \\
\hline CFRA 1267 & 2005 & & 179.85 & $\mathrm{c}$ & & 275.36 & o & & 1.54 & $\mathrm{n}$ & & 16.15 & $\mathrm{mn}$ & 1.53 \\
\hline F. virginiana & & & & & & & & & & & & & & \\
\hline JP 95-1-1 & 2004 & & 104.03 & ef & & 300.26 & mo & & 2.89 & $1 \mathrm{~m}$ & & 49.73 & $\mathrm{~cd}$ & 2.89 \\
\hline JP 95-1-1 & 2005 & & 109.17 & ef & & 302.08 & lmno & & 2.69 & $\operatorname{lmn}$ & & 45.40 & cdefg & 2.77 \\
\hline JP 95-9-6 & 2004 & & 30.49 & nop & & 295.59 & lmo & & 9.61 & $\mathrm{e}$ & & 26.72 & hijklm & 9.69 \\
\hline JP 95-9-6 & 2005 & & 59.66 & ijk & & 385.65 & hijk & & 6.47 & $f$ & & 44.93 & def & 6.46 \\
\hline LH 50-4 & 2004 & & 170.74 & $\mathrm{c}$ & & 452.81 & def & & 2.65 & $\operatorname{lm}$ & & 37.40 & efghi & 2.65 \\
\hline LH 50-4 & 2005 & & 139.16 & $\mathrm{~d}$ & & 374.56 & hijkn & & 2.70 & $\operatorname{lm}$ & & 39.79 & defgh & 2.69 \\
\hline NC 96-5-3 & 2004 & & - & - & & - & - & & - & - & & - & - & - \\
\hline NC 96-5-3 & 2005 & & - & - & & 813.44 & $\mathrm{a}$ & & - & - & & - & - & - \\
\hline NC 96-35-2 & 2004 & & 68.72 & ghij & & 394.84 & fghij & & 5.75 & $\mathrm{fg}$ & & 33.13 & ghi & 5.75 \\
\hline NC 96-35-2 & 2005 & & 72.72 & ghij & & 421.45 & efgh & & 5.88 & fg & & 37.42 & efghi & 5.80 \\
\hline NC 96-48-1 & 2004 & & 65.87 & hij & & 345.73 & $\mathrm{jklm}$ & & 5.25 & ghi & & 57.88 & bc & 5.25 \\
\hline NC 96-48-1 & 2005 & & 60.85 & ij & & 304.14 & lmo & & 5.06 & ghi & & 64.65 & $a b$ & 5.00 \\
\hline F. virginiana ssp. glat & uca & & & & & & & & & & & & & \\
\hline CFRA 0982 & 2004 & & - & - & & - & - & & - & - & & - & - & - \\
\hline CFRA 0982 & 2005 & & 200.72 & $\mathrm{~b}$ & & 480.73 & cde & & 2.40 & $\operatorname{lmn}$ & & 46.13 & def & 2.40 \\
\hline F. virginiana ssp. gra & yana & & & & & & & & & & & & & \\
\hline NC 95-19-1 & 2004 & & 220.75 & $\mathrm{a}$ & & 534.68 & $\mathrm{bc}$ & & 2.43 & $\operatorname{lmn}$ & & 47.70 & cde & 2.42 \\
\hline NC 95-19-1 & 2005 & & 206.10 & $a b$ & & 392.49 & fghij & & 1.91 & $\mathrm{mn}$ & & 30.62 & hij & 1.90 \\
\hline NC 95-21-1 & 2004 & & 78.69 & gh & & 352.40 & ijklm & & 4.49 & i & & 31.31 & hij & 4.48 \\
\hline NC 95-21-1 & 2005 & & 117.62 & $\mathrm{e}$ & & 393.77 & fghij & & 3.36 & $\mathrm{jkl}$ & & 29.14 & hijk & 3.35 \\
\hline F. virginiana ssp. virg & iniana & & & & & & & & & & & & & \\
\hline CFRA 1177 & 2004 & & 32.31 & nop & & 314.94 & klmo & & 9.67 & e & & 44.71 & defg & 9.75 \\
\hline CFRA 1177 & 2005 & & - & - & & - & - & & - & - & & - & - & - \\
\hline Frederick 9 & 2004 & & 55.08 & $\mathrm{jklm}$ & & 325.95 & jklmo & & 5.84 & fgh & & 16.59 & $\mathrm{klmn}$ & 5.92 \\
\hline Frederick 9 & 2005 & & 75.30 & ghi & & 364.22 & hijkl & & 4.86 & ghi & & 27.12 & ijkl & 4.84 \\
\hline Montreal River 10 & 2004 & & 42.61 & Imno & & 487.60 & $\mathrm{~cd}$ & & 11.50 & cd & & 29.60 & hijk & 11.44 \\
\hline Montreal River 10 & 2005 & & 43.26 & lmno & & 451.96 & defg & & 10.43 & de & & 36.36 & fghi & 10.45 \\
\hline RH 30 & 2004 & & - & - & & - & - & & - & - & & - & - & - \\
\hline RH 30 & 2005 & & 175.31 & $\mathrm{c}$ & & 567.70 & $\mathrm{~b}$ & & 3.25 & $\mathrm{kl}$ & & 11.51 & $\mathrm{n}$ & 3.24 \\
\hline Significance & & $\mathrm{df}$ & Mean square & & $\mathrm{df}$ & Mean square & & df & Mean square & & $\mathrm{df}$ & Mean square & & \\
\hline Genotype & & 17 & $11,282.0$ & $* *$ & 18 & $40,454.1$ & $* *$ & 17 & 596.2 & $* *$ & 17 & $10,974.5$ & $* *$ & \\
\hline Year & & 1 & 275.9 & $*$ & 1 & 1.2 & NS & 1 & 139.3 & $*$ & 1 & 117.9 & NS & \\
\hline Genotype $\times$ year & & 12 & 317.2 & $* *$ & 12 & 4049.0 & $* *$ & 12 & 105.8 & $* *$ & 12 & 606.6 & $* *$ & \\
\hline Error & & 23 & 60.0 & & 24 & 922.0 & & 23 & 26.5 & & 23 & 117.7 & & \\
\hline
\end{tabular}

${ }^{\mathrm{z}}$ Data expressed as micrograms of cyanidin 3-glucoside equivalents per gram fresh weight (FW).

${ }^{\mathrm{y}}$ Data expressed as micrograms of pelargonidin 3-glucoside equivalents per gram $\mathrm{FW}$.

${ }^{\mathrm{x}}$ Means within same column followed different letter are significantly different at $P=0.05$.

NS, ${ }^{*}{ }^{* *}$ Nonsignificant, significant at $P=0.05$ and $P=0.01$ respectively. 
CFRA 0982, NC 96-5-3, and RH 30, because these accessions were higher in antioxidant capacity, total anthocyanins, and total phenolics than the top-ranking $F$. Xananassa accession tested.

\section{Literature Cited}

Ames, B.M., M.K. Shigena, and T.M. Hagen. 1993. Oxidants, antioxidants and the degenerative diseases of aging. Proc. Natl. Acad. Sci. USA 90:7915-7922.

Black, B.L., J.M. Enns, and S.C. Hokanson. 2002. A comparison of temperate-climate strawberry production systems using eastern genotypes. HortTechnology 12:670-675.

Cerdá, B., F.A. Tomás-Barberán, and J.C. Espín. 2005. Metabolism of antioxidant and chemopreventive ellagitannins from strawberries, raspberries, walnuts, and oak-aged wine in humans: Identification of biomarkers and individual variability. J. Agr. Food Chem. 53: 227-235.

Cheng, G.W. and P.J. Breen. 1991. Activity of phenylalanine ammonialyase (PAL) and concentrations of anthocyanins and phenolics in developing strawberry fruit. J. Amer. Soc. Hort. Sci. 116:865-869.

Clegg, K.M. and A.D. Morton. 1968. The phenolic compounds of blackcurrant juice and their protective effect on ascorbic acid. II. The stability of ascorbic acid in model systems containing some of the phenolic compounds associated with black currant juice. J. Food Technol. 3:277-284.

Daniel, E.M., A.S. Krupnick, Y.H. Heur, J.A. Blinzler, R.W. Nims, and G.D. Stoner. 1989. Extraction, stability, and quantification of ellagic acid in various fruits and nuts. J. Food Chem. Composition Analysis 2:338-349.

Darrow, G.M. 1966. The strawberry. History, breeding and physiology. Holt, Rinehart and Winston, New York.

Dragsted, L.O., M. Strube, and J.C. Larsen. 1993. Cancer-protective factors in fruits and vegetables: Biochemical and biological background. Pharmacol. Toxicol. 1:116-135.

Gil, M.I., D.M. Holcroft, and A.A. Kader. 1997. Changes in strawberry anthocyanins and other polyphenols in response to carbon dioxide treatments. J. Agr. Food Chem. 45:1662-1667.

Hancock, J.F., P.W. Callow, A. Dale, J.J. Luby, C.E. Finn, S.C. Hokanson, and K.E. Hummer. 2001a. From the Andes to the Rockies: Native strawberry collection and utilization. HortScience 36:221-225.

Hancock, J.F., C.A. Finn, S.C. Hokanson, J.J. Luby, B.L. Goulart, K. Demchak, P.W. Callow, S. Serçe, A.M.C. Schilder, and K.E. Hummer. 2001b. A multistate comparison of native octoploid strawberries from North and South America. J. Amer. Soc. Hort. Sci. 126:579-586.

Hancock, J.F., S.C. Hokanson, C.E. Finn, and K.E. Hummer. 2002. Introducing a supercore collection of wild octoploid strawberries. Acta Hort. 567:77-79.

Heinonen, I.M., A.S. Meyer, and E.N. Frankel. 1998. Antioxidant activity of berry phenolics on human low-density lipoprotein and liposome oxidation. J. Agr. Food Chem. 46:4107-4112.

Huang, D., B. Ou, M. Hampsch-Woodill, J.A. Flanagan, and R.L. Prior. 2002. High-throughput assay of oxygen radical absorbance capacity (ORAC) using a multichannel liquid handling system coupled with a microplate fluorescence reader in 96-well format. J. Agr. Food Chem. 50:4437-4444.

Kuehnau, J. 1976. The flavonoids. A class of semi-essential food components: Their role in human nutrition. World Rev. Nutr. Diet. 24:117-191.

Lewers, K.S., J.M. Enns, S.Y. Wang, J.L. Maas, G.J. Galletta, S.C. Hokanson, J.R. Clark, K. Demchak, R.C. Funt, S.A. Garrison, G.L. Jelenkovic, G.R. Nonnecke, P.R. Probasco, B.J. Smith, B.R. Smith, and C.A. Weber. 2004. 'Ovation' strawberry. HortScience 39: 1785-1788.

Maas, J.L., S.Y. Wang, and G.J. Galletta. 1991. Evaluation of strawberry genotypes for ellagic acid, an antimutagenic and anticarcinogenic plant phenol, p. 115-117. In: A. Dale and J.J. Luby (eds.). The strawberry into the 21 st century. Timber Press, Portland, OR.

Okuda, T., T. Yoshida, and T. Hatano. 1989. Ellagitannins as active constituents of medical plants. Planta Med. 55:117-122.

Pinkerton, J. and C.E. Finn. 2005. Responses of strawberry species and cultivars to the root-lesion and northern root-knot nematodes. HortScience 40:33-38.

Satué-Gracia, M.T., I.M. Heinonen, and E.N. Frankel. 1997. Anthocyanins as antioxidants on human low-density lipoprotein and lecithin-liposome systems. J. Agr. Food Chem. 45:3362-3367.

Slinkard, K. and V.L. Singleton. 1997. Total phenol analysis: Automation and comparison with manual methods. Amer. J. Enol. Viticult. 28:49-55.

Sondheimer, E. and C.B. Karash. 1956. The major anthocyanin pigments of the wild strawberry (Fragaria vesca). Nature 178:648-649.

Starvic, B., T.I. Matula, R. Klassen, R.H. Downie, and R.J. Wood. 1992. Effect of flavonoids on mutagenicity and bioavailability of xenobiotics in food, p. 239-249. In: M.T. Huang, C.T. Ho, C.Y. Lee (eds.). Phenolic compounds in food and their effects on health II. Antioxidants \& cancer prevention. Amer. Chem. Soc. Symp. Ser. 507, Washington, DC.

Velioglu, Y.S., G. Mazza, L. Gao, and B.D. Oomah. 1998. Antioxidant activity and total phenolics in selected fruits, vegetables, and grain products. J. Agr. Food Chem. 46:4113-4117.

Wang, H., G. Cao, and R.L. Prior. 1996. Total antioxidant capacity of fruits. J. Agr. Food Chem. 44:701-705.

Wang, S.Y., J.A. Bunce, and J.L. Maas. 2003. Elevated carbon dioxide increases contents of antioxidant compounds in field-grown strawberries. J. Agr. Food Chem. 51:4315-4320.

Wang, S.Y. and H.S. Lin. 2000. Antioxidant activity in fruits and leaves of blackberry, raspberry, and strawberry varies with cultivar and developmental stage. J. Agr. Food Chem. 48:140-146.

Wang, S.Y. and H.S. Lin. 2003. Compost as a soil supplement increases the level of antioxidant compounds and oxygen radical absorbing capacity in strawberry. J. Agr. Food Chem. 51: 6844-6850.

Wang, S.Y. and W. Zheng. 2001. Effect of plant growth temperature on antioxidant capacity in strawberry. J. Agr. Food Chem. 49: 4977-4982.

Wang, S.Y., W. Zheng, and G.J. Galletta. 2002. Cultural system affects fruit quality and antioxidant capacity in strawberries. J. Agr. Food Chem. 50:6534-6542.

Zheng, W. and S.Y. Wang. 2003. Oxygen radical absorbing capacity of phenolics in blueberries, cranberries, chokeberries, and lingonberries. J. Agr. Food Chem. 51:502-509. 